\title{
Thioarsenic compounds exist in the drinking groundwater
}

\author{
J.H. Liang ${ }^{1} \&$ Z. Chen ${ }^{2}$ \\ ${ }^{1}$ Key Laboratory of Karst Ecosystem and Treatment of Rocky Desertification, Institute of Karst Geology, \\ Chinese Academy of Geological Sciences, Guilin, P.R. China \\ ${ }^{2}$ Department of Environmental Science, Xi'an Jiaotong-Liverpool University, Suzhou, P.R. China
}

\begin{abstract}
Arsenic (As) polluted groundwater in Northern China was used as drinking water source and caused severe health problems. Characterization of As speciation is crucial to understand the health risk of As and its biogeochemical behaviors in groundwater. In this study, groundwater samples were collected from 26 wells in Northern China. Arsenic species in the groundwater were measured by high-performance liquid chromatography (HPLC) and inductively coupled plasma mass spectrometry (ICP-MS). Thioarsenate, one of the As species that is seldom reported in drinking groundwater, was detected in two-third of the sampling wells, even in the samples with total As concentration lower than $10 \mu \mathrm{g} \cdot \mathrm{L}^{-1}$. Furthermore, the occurrence of thioarsenate in groundwater samples was dependent on the $\mathrm{pH}$ of groundwater, and thioarsenate was transformed to arsenite below a $\mathrm{pH}$ value of 8.2. The study demonstrated thioarsenate was prevalent in the alkaline drinking groundwater and would be a new As exposure pathway for the people and livestock living in the As-rich area.
\end{abstract}

\section{INTRODUCTION}

Arsenic (As) thiolation occurs under alkaline reducing conditions with high sulfur concentration (Chen et al., 2005). The formation, stability and toxicity of thioarsenate have been investigated in the laboratory (Rader et al., 2004; Stauder et al., 2005; Stucker et al., 2014). Thioarsenate was found in the alkaline geothermal waters with high sulfur content (Planer-Friedrich et al., 2007) and groundwater from the contaminated site with industrial As (Wallschlager \& Stadey, 2007). Besides, thioarsenates were detected and contributed up to $33 \%$ of the As speciation in stream of an As-enriched peatland (Thomas Arrigo et al., 2016). Although there are some reports of thioarsenate in the natural groundwater (Stauder et al., 2005), it remains unclear that whether the thioarsenate exits in drinking groundwater.

Although the majority of As species in the groundwater in Northern China were identified as As(III) and $\operatorname{As}(\mathrm{V})$, the occurrence and formation of other As species are not well understood. In this study, the objectives were to clarify the As species profile with updated preservation methods and reveal the key environmental factors affecting the speciation of As in groundwater.

\section{METHODS}

\subsection{Sampling areas}

The sampling was conducted in the southern Datong basin of Shanxi province (Shanyin country) of Northern China where groundwater is the most heavily contaminated by As in China. The studied area is the Cenozoic basin located at the Shanxi Rift System. The $\mathrm{pH}$ values of groundwater we investigated were documented under partial alkaline condition.

\subsection{Laboratory analysis}

Arsenic species in fresh groundwater were analyzed using high-performance liquid chromatography (HPLC, 1100, Agilent, USA) and inductively coupled plasma mass spectrometry (ICP-MS, Agilent 7500, USA). A PRP-X100 anion-exchange column $(250 \times 4.1 \mathrm{~mm}, 10 \mu \mathrm{m})$ (Hamilton Co., Reno, NV, USA) was used for separation of As(III), As(V) and thioarsenate at room temperature $\left(25^{\circ} \mathrm{C}\right)$ with the mobile phase of $10 \mathrm{mM}\left(\mathrm{NH}_{4}\right)_{2} \mathrm{HPO}_{4}$ and $10 \mathrm{mM}$ $\mathrm{NH}_{4} \mathrm{NO}_{3}$ (pH 6.2).

The samples were also analyzed by HPLC-ICPMS with size exclusive column (Shodex OHpak SB$802.5 \mathrm{HQ}, 30 \mathrm{~cm} \times 8.0 \mathrm{~mm} \times 6.0 \mu \mathrm{m}$, Showa Denko America Inc., New York, NY, USA) to test the potential complexation of As with other large molecules. (Liu et al., 2011). The total As in filtered samples was detected by ICP-MS.

\section{RESULTS AND DISCUSSION}

\subsection{Determination of As species}

The total As concentrations of $90 \%$ groundwater samples exceeded $10 \mu \mathrm{g} \cdot \mathrm{L}^{-1}$, which is WHO guideline value for As for drinking water. The highest concentration of As was $703.7 \mu \mathrm{g} \cdot \mathrm{L}^{-1}$. No methylated As 


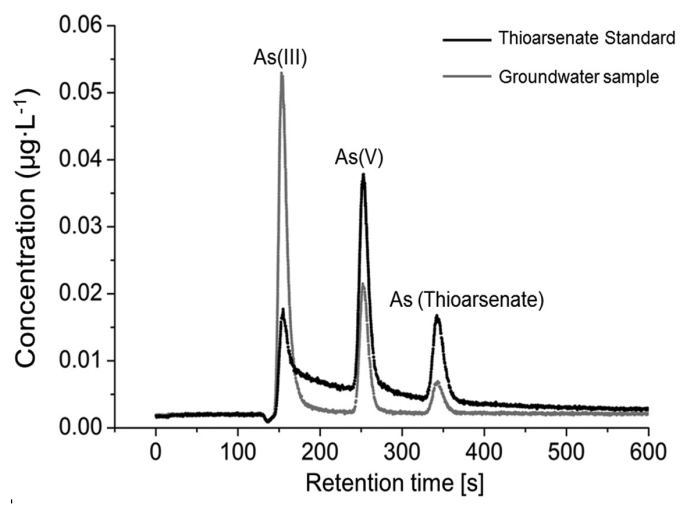

Figure 1. Arsenic speciation in field sample (gray line) and thioarsenate standard (black line) from HPLC-ICP-MS chromatograms. Elution order of arsenic speciation: As(III), As (V), As (Thioarsenate).

and NOM (Natural Organic Matter)-As complexation was detected in the groundwater samples. The As methylation was well observed in high organic matter conditions, like paddy field, but was not found in groundwater. $\mathrm{As}(\mathrm{III})$ and $\mathrm{As}(\mathrm{V})$ were dominant in all the samples.

One unidentified As compound, with the exception of $\mathrm{As}(\mathrm{III})$ and $\mathrm{As}(\mathrm{V})$, was observed in most samples and the retention time of its peak was $346 \mathrm{~s}$, same to thioarsenate standard (Fig. 1). Thioarsenate is unstable under acidic condition and has been widely reported in high sulfur condition (Jia et al., 2015). Although structure of the putative thioarsenate was not determined in this study because of its low concentration in field samples, the alkaline environment and high sulfur level in the investigated groundwater of the study sites provides a suitable geochemical condition for the thioarsenate formation. Other studies showed the concentrations of $\mathrm{SO}_{4}^{2-}$ in the investigated area varied from $0.02-3121 \mathrm{mg} \cdot \mathrm{L}^{-1}$ with the geological heterogeneity.

\subsection{Occurrence of thioarsenate}

The standard thioarsenate was artificially synthesized by mixing arsenite and sulfide, and measured by $\left(\mathrm{NH}_{4}\right)_{2} \mathrm{HPO}_{4}$ mobile phase at pHs 6.2, 7.2, 8.2 and 9.2. Along with the $\mathrm{pH}$ gradient, the retention time of thioarsenate was gradually reduced from $435 \mathrm{~s}$ at $\mathrm{pH}$ 9.2 to $342 \mathrm{~s}$ at $\mathrm{pH}$ 6.2. The $\mathrm{pH}$ variation in mobile phase resulted in the change of the percentage of As(III), $\mathrm{As}(\mathrm{V})$ and thioarsenate. In the investigated $\mathrm{pH}$ range, the percentage of $\mathrm{As}(\mathrm{V})$ was slightly varied. Thioarsenate was converted to As(III) at low $\mathrm{pH}$. When the $\mathrm{pH}$ of mobile phase decreased from 8.2 to 7.2 and 6.2, the percentage of $\mathrm{As}(\mathrm{III})$ increased from $18 \%$ to
$23 \%$ and $40 \%$, and in the meantime, the thioarsenate contents dropped from $37 \%$ to $31 \%$ and $18 \%$ respectively. The results indicated that monothioarsenate was transformed into arsenite at the $\mathrm{pH}$ lower than 8.2 in the groundwater.

\section{CONCLUSIONS}

The results suggested that thioarsenate would be a new As exposure pathway for human health, especially for the people living in the As-contaminated area of Northern China. The conversion between thioarsenate and arsenite was found at a $\mathrm{pH}$ threshold of 8.2. The sensitivity of thioarsenate to $\mathrm{pH}$ provides a way to control its formation or degradation. This study improved our understanding of As species and interconversion of As in the natural drinking groundwater. Further investigation is required to elucidate the formation mechanism of thioarsenate in alkali groundwater and reveal the consequence when people or animals are exposed to thioarsenate through mouth.

\section{ACKNOWLEDGEMENTS}

Financial support was obtained from Cooperation @epfl (SDC-EPFL fund, project: Relevance of arsenic complexed with organic matter in Chinese groundwater) and the Natural Science Foundation of China (No. 41371459 and No. 41571305).

\section{REFERENCES}

Chen, Z., Zhu, Y.G., Liu, W.J. \& Meharg, A.A. 2005. Direct evidence showing the effect of root surface iron plaque on arsenite and arsenate uptake into rice (Oryza sativa) roots. New Phytol. 165: 91-97.

Jia, Y., Bao, P. \& Zhu, Y.G. 2015. Arsenic bioavailability to rice plant in paddy soil: influence of microbial sulfate reduction. J. Soils Sediments 15: 1960-1967.

Planer-Friedrich, B., London, J., McCleskey, R.B., Nordstrom, D.K. \& Wallschlager, D. 2007. Thioarsenates in geothermal waters of yellow stone national park: Determination, preservation, and geochemical importance. Environ. Sci. Technol. 41: 5245-5251.

Stucker, V.K., Silverman, D.R., Williams, K.H., Sharp, J.O. \& Ranville, J.F. 2014. Thioarsenic species associated with increased arsenic release during biostimulated subsurface sulfate reduction. Environ. Sci. Technol. 48: 13367-13375.

Thomas Arrigo, L.K., Mikutta, C., Lohmayer, R., PlanerFriedrich, B. \& Kretzschmar, R. 2016. Sulfidization of organic freshwater flocs from a minerotrophic peatland: speciation changes of iron, sulfur, and arsenic. Environ. Sci. Technol. 50: 3607-3616.

Wallschlager, D. \& Stadey, C.J. 2007. Determination of (oxy)thioarsenates in sulfidic waters. Anal. Chem. 79:3873-3880. 